\title{
The Importance of Thermal Barrier Coating in Compression and Spark Ignition Engines
}

\author{
Isaac Oamen Festus, Edema Ofuafo Anthony
}

\begin{abstract}
This paper explains the importance of applying thermal barrier coating (TBC) technique in internal combustion engines by providing an effective way of reducing gas emission which are carbon monoxide (CO), oxide of nitrogen $\left(\mathrm{NO}_{X}\right)$, hydrocarbon (HC) including particulate matter (PM) thereby increasing engine performance (brake thermal efficiency) achieved by applying coating layers on some internal combustion engine parts using materials with low thermal conductivities and matched coefficients of thermal expansion (CTE close to the substrate material) which are mainly ceramics. Energy demand for various activities of life is increasing on a daily basis. The world depends majorly on non-renewable energy sources from fossil fuels to meet these energy demands. To be comfortable in life, better means of transportation and provision of power are required. Compression and spark ignition engines which are also called Internal Combustion Engines (ICEs) provide better transport facilities and power. However, combusting these fuels in automobile and stationary engines produces unfriendly atmosphere, contaminates water and air that are consumed by man. Pollution created as a result of combustion of gases in ICE is one of the worst man made contribution to atmospheric pollution.
\end{abstract}

Keywords: Internal Combustion Engines (ICEs), Brake Thermal Efficiency, Thermal Conductivity, Coefficient of Thermal Expansion, Thermal Barrier Coating.

\section{INTRODUCTION}

Thermal barrier coatings are advanced ceramic materials administered on metallic surfaces, like turbine, aero-engine, and spark and compression ignition engine parts (cylinder head, cylinder liner, valves, piston head, etc.), working at very high temperatures [1]. Coatings help to insulate metallic parts from heavy and excessive heat loads using thermally insulating materials which withstand reasonable temperature difference between the combustion chamber and coating surfaces [2]. By so doing, high operating temperatures are achieved on the metallic (component) surfaces, components life extended when oxidation and thermal fatigue problems are reduced. Modern coating systems act as insulators to heat transfer through metallic surfaces in order to protect engine components from oxidation and hot corrosion [2]-[3].

Coatings are not new invention [4].

Revised Manuscript Received on April, 182020.

* Correspondence Author

Engr. Isaac Oamen Festus*, Lecturer, Department of Mechanical Engineering, Edo University Iyamho, Uzairue, Edo State. E-mail: isaac.oamen@edouniversity.edu.ng

Engr. Edema Ofuafo Anthony, Lecturer, Department of Mechanical Engineering, Delta State Polytechnic, Otefe-Oghara, Delta State. E-mail: aoedema@gmail.com

(c) The Authors. Published by Blue Eyes Intelligence Engineering and Sciences Publication (BEIESP). This is an open access article under the CC BY-NC-ND license (http://creativecommons.org/licenses/by-nc-nd/4.0/)
Their applications started long ago where painting of wood and metal with organic and inorganic pigments to improve their aesthetic appearances and environmental stabilities were always carried out [5]. Paint coatings were mainly applied to reduce corrosion, wear and abrasion resistance of the substrate materials [2]. However, paint coatings could not be relied upon because withstanding elevated temperatures and adhering to metallic surfaces properly were the major disadvantages [10]-[5]. Modern high performance machines that are subjected to extreme temperatures and mechanical stresses, need surface protection against high temperature corrosive media and mechanical wear and tear hence the need for the modern coating systems [4]. Modern coatings which are highly versatile with low cost technique and carried out with minimum equipment investment that require easy training procedures for the operator are now embraced [6]. Thermal spraying was one of the modern coating methods adopted. Thermal spraying is the process of partially or completely melting a wire, rod or powder as it passes through a high temperature process generated electrically by a gas plasma or by a combustion gas flame [7]. The molten droplets produced then form a coating layer on the substrate. This coating process is widely applied on metallic parts to rebuild and address wear [6]. Thermal barrier coating using alumina or zirconia are applicable in the aerospace and automotive industries including high temperature-erosion protection of boiler tubes and fire chambers of coal-fired power plants, corrosion protection of special concrete parts and bioceramic coatings for orthopedic and dental prosthetic [5].

Advanced materials (ceramics) coatings, became more popular among materials engineers [8]. The availability of coating equipment, easy application of coating to metallic surfaces and availability of materials make metal surface coatings acceptable [5]-[9].

Heat transfer from combustion chamber to the coolant in internal combustion engines (ICEs) varies between 25 $35 \%$ of the total energy produced by the mixture of fuel and combustion [11]-[12]. Heat is convected, conducted and radiated through the cylinder walls as heat lost and some of the remaining heat is transferred to the coolant in the cylinder head with more heat transfer near the exhaust valve seats [13]. When operating ICEs, energy losses via heat transfer to the cylinder walls during the latter stages of the compression stroke and the combustion-expansion stroke occurs [5]. Similarly, during the compression process, the charged temperature increases above the wall temperature, hence heat transfer occurs from the combustion chamber to the cylinder walls. In the combustion-expansion stroke, the heat transfer rate to the cylinder walls is the highest [14]-[15].

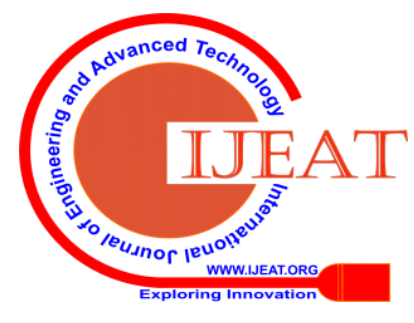




\section{The Importance of Thermal Barrier Coating in Compression and Spark Ignition Engines}

However, with TBC the heat lost to the coolant and through the cylinder wall will decrease and be converted to useful work [16].

\section{METHODOLGY}

In this paper, the method applied is literature review and research on the structure of thermal barrier coating, ceramics material for thermal barrier coating and the advantages of thermal barrier coating in internal combustion engines.

\section{A. Structure of a Thermal Barrier Coating}

TBC comprises several material layers to ensure good performance. Each has a different function. TBC consists of three layers. The first one is the top coat a ceramic layer, under it there is the metallic alloy layer of bond coat directly coated on the substrate [17]. The metallic substrate is part of the TBC layers since all the materials have to be matched by their physical properties to create robust TBC's. A third layer called thermally grown oxide (TGO) is generated between the top and bond coat layers [18]. Since the substrate is a layer in most cases, them the TBC will now be composed of four layers. However, some literatures often neglect the metallic substrate as a layer [10]. It is advisable to choose a substrate material which will give good values of surface roughness in order for the upcoming layers of the coating to deposit easily on it [19]. Surface roughness is artificially modified by using abrasive grit blasting which mould the shape, make it rougher and easier for the mechanical adhesion of the bond coat. In Fig. 1 [20], one can see the position of the substrate material as well as the layers conforming the coating [20].

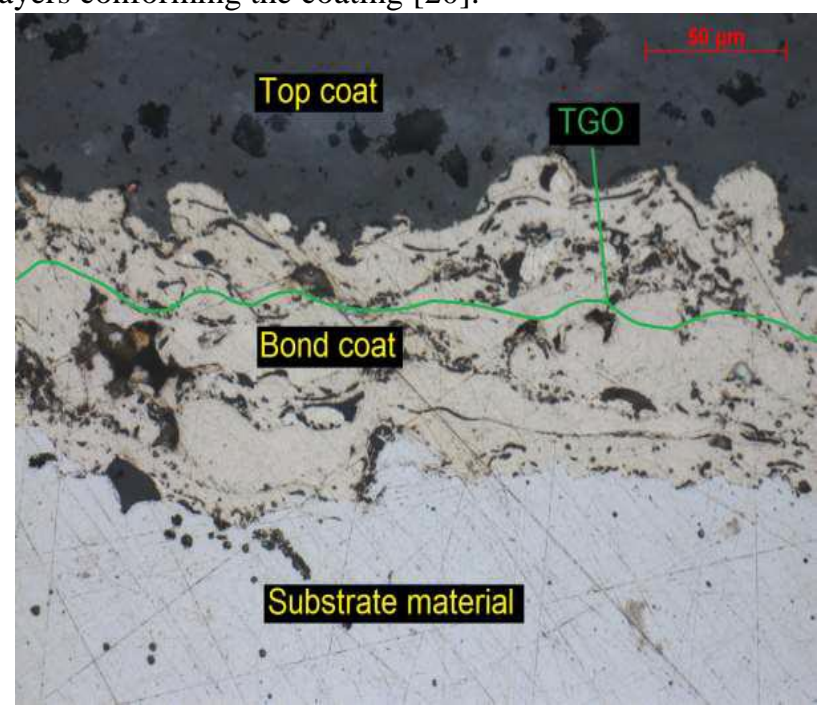

Fig. 1 [20]. Cross section of YSZ

The bond coat layer is a metallic layer made of nanostructured metallic composite (including $\mathrm{Ni}$ or $\mathrm{Cr}$ or both for example) and has several functions. Some of the functions are reducing mismatch in coefficient of thermal expansion between the ceramic coating and metal substrate [21]. Other functions are improving the adhesiveness of the top coat to the substrate and reducing oxygen penetration to the substrate. At elevated temperatures, the bond coat layer slowly undergoes oxidation generating on the surface of the TGO [18]. The ceramic top coat layer is typically made of metal oxides i.e. $\mathrm{ZrO}_{2}, \mathrm{Al}_{2} \mathrm{O}_{3}, \mathrm{TiO}_{2}$, etc. and is a thicker layer than the bond coat layer. Its major function is protecting materials beneath from elevated temperatures [22]-[23]. The main characteristic of the top coat material is its very low heat conductivity which is further enhanced by making it porous. Porosity influences coatings in its ability to withstand thermal stresses [23]. Top coat layer with very low porosity has the lowest toughness which makes it accumulates largest compressive residual stresses. Secondly, a top coat layer with high porosity has higher toughness which makes it accumulates less compressive residual stresses [21].

As mentioned before, thermally grown oxide forms under high temperature conditions in the interface between bond and top coat layers and it originates from the bond coat material. Oxygen at elevated temperatures is transported through the porous structure and micro cracks of the top coat layer to the bond coat layer surface to cause oxidation [14]. However, created oxides reduce further transportation of oxygen and protect the substrate underneath. Oxides composition depend on bond coat layer material and hence the right choice is very important. Aluminium containing bond coat oxides have low growth rate, uniformity and high density [23]. The continued formed layer is important for further growth of thermally grown oxide [21].

\section{B. Ceramic Materials for Thermal Barrier Coating (TBC)}

Several different TBC materials are evaluated over the years for ICE applications. A number of these materials are discussed below [11]:

- Zirconia $\left(\mathrm{ZrO}_{2}\right)$ : Zirconia is one of the popular ceramic coating materials [18]. The common mechanical property of zirconia is its high temperature resistance when considering ceramic coating application in ICEs. Other mechanical and physical properties are high melting point, durability against thermal shocks, good corrosion and erosion resistances [20]. This material is used in coating application for diesel engines and turbine blades to reduce heat transfer. Zirconia exist in three crystal structures as shown in Fig. 2 [11]. They are cubic (c), monolithic (m) and tetragonal (t) structures. Monolithic structure remains stable between room temperature and $1170{ }^{0} \mathrm{C}$ but transits to tetragonal structure above $1170{ }^{\circ} \mathrm{C}$. Tetragonal structure is however stable up to $2379{ }^{0} \mathrm{C}$ but above this temperature, the structure transforms to cubic structure [11].

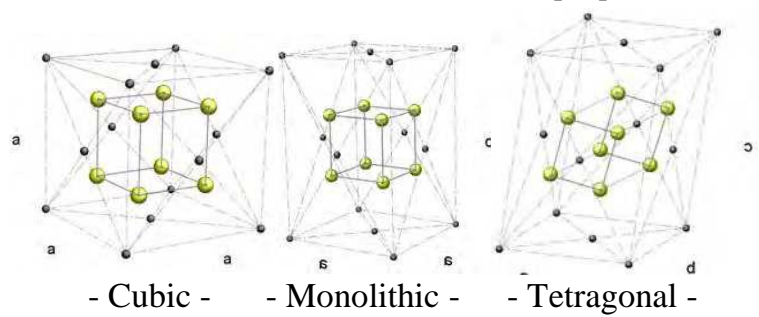

Fig. 2 [11]. Zirconia in three crystal structures

Some advantages of zirconates are as follows: low sintering activity; low thermal conductivity and good thermal cycling resistance [11].

Blue Eyes Intelligence Engineering \& Sciences Publication

(C) Copyright: All rights reserved.

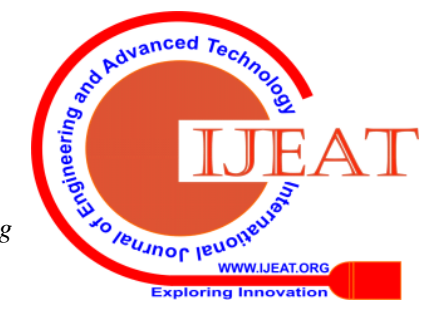


Similarly, some disadvantages of zirconates is low coefficient of thermal expansion (not matching with substrate material) which causes residual stress in the coating, and this leads to coating delamination.

It is recommended that zirconates should be stabilized with other ceramic material to avoid coating delamination [14].

- Yttria Stabilized Zirconia $\left(\mathrm{Y}_{2} \mathrm{O}_{3}-\mathrm{ZrO}_{2}\right)$ : The ceramic frequently used as a top coat layer in aero and industrial turbines and in diesel engine tests, is yttria partially stabilized zirconia (YSZ). Pure zirconia, $\mathrm{ZrO}_{2}$, possesses many of the required properties listed above, but undergoes detrimental tetragonal-to-monoclinic phase transformation during cooling [22]. This is associated with an increase in volume of approximately 3-5\%, which may result in coating failure. Zirconia is therefore normally stabilized with 6-8 wt\% yttria $\left(\mathrm{Y}_{2} \mathrm{O}_{3}\right)$. With these yttria contents, YSZ coatings have compositions placing them in a two-phase region of the phase diagram, where yttrium-lean tetragonal and yttrium-rich cubic phases are found (see Fig. 3 [20]). However, due to rapid cooling during the coating processes, a metastable $t^{\prime}$ phase is formed instead of the two-phase mixture [20]. When made to undergo high temperatures, the $\mathrm{t}^{\prime}$ phase is decomposed through diffusion into a two-phase mixture of the cubic and tetragonal phases [18]. This causes spallation of the coating as a result of volume change when tetragonal phase later turns to the monoclinic phase. However, the $t^{\prime}$ phase can be expected to be stable at the relatively low temperatures in a diesel engine [19]. Additions of yttria or other stabilizers result in a significant number of vacancies, which are effective in scattering phonons and reduce the thermal conductivity of the material [17]. Also, the type of deposition process greatly influences the thermal conductivity of the coating. For 6-8 wt\% YSZ, the thermal conductivity is typically 1.8$2.0 \mathrm{Wm}^{-1} \mathrm{~K}^{-1}$ for Electron beam - physical vapour deposition (EB-PVD) coatings and can be as low as 0.9 $\mathrm{Wm}^{-1} \mathrm{~K}^{-1}$ for plasma-sprayed coatings [16]. The coefficient of thermal expansion (CTE) is $10.7 \times 10^{-6} \mathrm{~K}^{-1}$ for plasmasprayed YSZ with 7-8 wt \% $\mathrm{Y}_{2} \mathrm{O}_{3}$ in the $30-1000^{\circ} \mathrm{C}$ temperature interval [21]. This is close to the CTE of steel and cast iron. A close coefficient of thermal expansion match is necessary to reduce stresses during thermal cycling. Hence, 7-8\% yttria stabilized zirconia has match CTE, low thermal conductivity and high thermal shock resistance [20]. This ceramic coating material is highly recommended in ICEs applications [21].

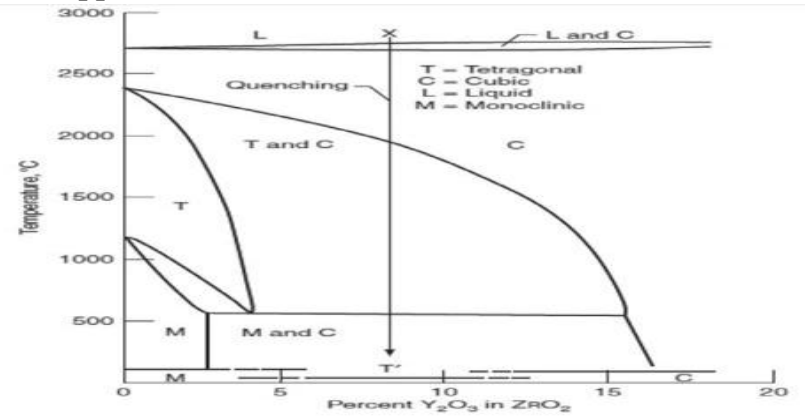

Fig. 3 [20]. Phase diagram of yttria-stabilized zirconia
- Yttria $\left(\mathrm{Y}_{2} \mathrm{O}_{3}\right)$ : This material has mechanical and physical properties of high melting point which is 2410 ${ }^{0} \mathrm{C}$, high stability in air, not easy to reduce and easily dissolve in acids and absorbs $\mathrm{CO}_{2}$ [20]. If added to zirconia, it stabilizes the material in cubic structure. The primary yttria minerals are classified as gadolinite, xenotime and fergusonite [18].

- Mullite $\left(3 \mathrm{Al}_{2} \mathrm{O}_{3}-2 \mathrm{SiO}_{2}\right)$ : A number of top coat materials that have insufficient temperature stability for turbine applications may still be of interest for internal combustion engines as a result of their lower temperatures [18]. Example of such material is mullite $\left(3 \mathrm{Al}_{2} \mathrm{O}_{3}-2 \mathrm{SiO}_{2}\right)$. It has been shown that plasma-sprayed mullite contains amorphous phases, which crystallize and decrease in volume at temperatures of $750^{\circ} \mathrm{C}-1000^{\circ} \mathrm{C}$ [19]. Volume contraction, along with a low CTE $\left(4.5 \times 10^{-6} \mathrm{~K}^{-1}\right.$ between room temperature and $1400^{\circ} \mathrm{C}$ ) [20] leads to cracks in the top coat layer and to spallation [21]. This crystallization also increases the thermal conductivity of mullite [21]. However, issues with spallation and increase thermal conductivity due to crystallization during high-temperature exposure is avoided in diesel engines, where coating temperatures are fairly low [18]. Laboratory tests as well as thermal cycling tests of pistons have indicated that mullite top coats have less surface cracking and last longer than zirconia top coats. The limited number of surface cracks is due to the low relaxation of mullite at high temperatures [18]. However, compressive stresses can be maintained throughout the cooling cycle in mullite top coats [23]. Mullite is a vital material because of the following mechanical and physical properties [21]: low density, high thermal stability, stability in severe chemical environments, low thermal conductivity and favorable strength and creep behavior. When compared with yttria stabilized zirconia, it has low CTE, higher thermal conductivity and much more oxygen-resistant than yttria stabilized zirconia. However, the large mismatch in the CTE with metallic substrate results in poor adhesion. Other disadvantage of mullite is crystallization at 1023 $1273 \mathrm{~K}$ [21].

- Alumina $\left(\mathrm{Al}_{2} \mathrm{O}_{3}\right)$ : Alumina as a ceramic material possesses high hardness, chemical inertness, high thermal conductivity and low CTE when compared to yttria stabilized zirconia [5]. Despite not being a good thermal barrier coating material, its addition to yttria stabilized zirconia enhances hardness of the coating and improves oxidation resistance of the substrate. However, its disadvantages include phase transformation at 1273K, high thermal conductivity and very low coefficient of thermal expansion [21].

- Magnesia (MgO): Magnesia as a ceramic material has high melting point of $2800{ }^{\circ} \mathrm{C}$, very high CTE and easily reduced at elevated temperatures [18]. This material has resistance to mineral acids, acid gases, neutral salts and moisture at high temperatures. Mixing with carbon gives stability at $1800{ }^{\circ} \mathrm{C}$. However,

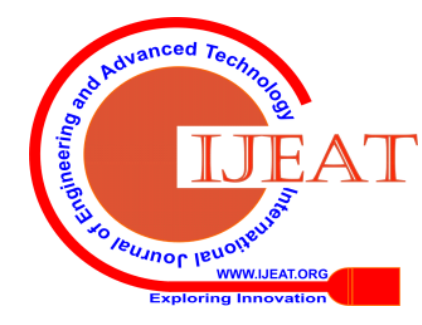




\section{The Importance of Thermal Barrier Coating in Compression and Spark Ignition Engines}

it will rapidly react with carbon and carbides over a temperature of $2000{ }^{0} \mathrm{C}$ [22].

- Spinel: Despite having a very good high melting point and chemical properties, its CTE prevents its uses as a reliable choice for thermal barrier coatings [18].

- Forsterite $\left(\mathrm{MgO}-2 \mathrm{SiO}_{2}\right)$ : Forsterite $\left(\mathrm{MgO}-2 \mathrm{SiO}_{2}\right)$ has a coefficient of thermal expansion (CTE) $11.0 \times 10^{-6} \mathrm{~K}^{-1}$ between 25 and $800{ }^{\circ} \mathrm{C}$. Its high CTE result in mismatching between forsterite and $80 \mathrm{Ni}-20 \mathrm{Cr}$ bond coat with steel substrate has led to good results in thermal cycling tests [23]. However, its thermal conductivity decreases with temperature, declining from about 1.8 $\mathrm{Wm}^{-1} \mathrm{~K}^{-1}$ at room temperature to $1.3 \mathrm{Wm}^{-1} \mathrm{~K}^{-1}$ at $1000^{\circ} \mathrm{C}$ [21]. Because of its high CTE a good match with the substrate is achieved. Moreover, at thicknesses of some hundred microns, a very good thermal shock is also guaranteed [18].

- Beryllia: This ceramic material possesses the following properties: high resistance to reduction, thermal stability, very thermal resistance, very low electrical conductivity, high compression strength at temperature of stability and melting point of $2550{ }^{\circ} \mathrm{C}$. Beryllia is a preferred ceramic material for molten metals because of its resistance to chemical materials [21]

- Gadolinium Zirconate $\left(\mathrm{Gd}_{2} \mathrm{Zr}_{2} \mathrm{O}_{7}\right)$ : Another type of ceramic material is the Gadolinium zirconate (GZ, $\mathrm{Gd}_{2} \mathrm{Zr}_{2} \mathrm{O}_{7}$ ) [5]. It is a ceramic with a pyrochlore structure. Gadolinium zirconate has excellent thermal stability which has encouraged it to be used at temperatures above $1300{ }^{\circ} \mathrm{C}$ [21]. The thermal conductivity of a plasma-sprayed GZ coating is about 20\% lower than that of plasma-sprayed YSZ. It has been demonstrated that GZ reacts with alumina in the thermally grown oxide (TGO) to form $\mathrm{GdAlO}_{3}$, which compromises the oxidation protection provided by the TGO [22]. However, to prevent this reaction, it is recommended that a diffusion barrier, such as YSZ, be used or that the temperature near the TGO be kept well below $1100^{\circ} \mathrm{C}$. Because bond coat temperatures in internal combustion engines in general are much lower than $1100{ }^{\circ} \mathrm{C}$ and this might not be a problem for such applications [22].

- Lanthanum Zirconate $\left(\mathrm{La}_{2} \mathrm{Zr}_{2} \mathrm{O}_{7}\right)$ : Lanthanum zirconate (LZ, $\mathrm{La}_{2} \mathrm{Zr}_{2} \mathrm{O}_{7}$ ) is another ceramic material with a pyrochlore structure [5]. Its fracture toughness is comparable to that of YSZ and its thermal conductivity is about 20\% lower than that of YSZ at very high temperatures. Other properties that make lanthanum zirconate interesting as a top coat layer is its low sintering tendency and high-temperature stability up to $2000{ }^{\circ} \mathrm{C}$ [19]. The coefficient of thermal expansion of lanthanum zirconate is $9.1 \times 10^{-6} \mathrm{~K}^{-1}$ at $30{ }^{0} \mathrm{C}-1000{ }^{0} \mathrm{C}$ which is lower than that of YSZ. This may lead to higher stresses in the coating due to a larger CTE mismatch with other layers in the TBC technology. However, results of thermal cycling tests of LZ and YSZ/LZ coatings have been very promising [5]. When materials are plasma sprayed, some constituents may be lost. In the case of $\mathrm{La}_{2} \mathrm{Zr}_{2} \mathrm{O}_{7}$ or $\mathrm{La}_{2} \mathrm{O}_{3}$, it easily evaporates which may lead to monoclinic and cubic $\mathrm{ZrO}_{2}$ in the coating [20]. Pure $\mathrm{ZrO}_{2}$ may undergo phase transformations at elevated temperatures, which causes spallation of the coating. At high temperatures, say $1400^{\circ} \mathrm{C}, \mathrm{LZ}$ has been observed to react with $\mathrm{Al}_{2} \mathrm{O}_{3}$, which exists in the TGO layer [18]. However, no reaction was seen at lower temperatures, so this is not expected to be a problem in internal combustion engine applications. Ionic conductivity is much lower for LZ than for YSZ. Oxygen is not as easily transported through the top coat, so bond coat oxidation rate can be expected to be lower [22].

\section{Advantages of Thermal Barrier Coating in Internal Combustion Engines}

Some of the advantages of thermal barrier coating in internal combustion engine parts are stated below:

1) High melting point: Coating materials should possess high melting points to enable them withstand high operating temperatures without melting away;

2) Low thermal conductivity: Coating materials should also possess very low thermal conductivities so that they produce considerable drop in temperatures across the coating layers;

3) Low density: Coating materials must have low densities and weights so as to reduce the payloads;

4) It has a high thermal shock resistance;

5) Resistance to oxidation and chemical environment: Coating materials should protect the underlying metals from oxidation and corrosion;

6) High surface emissivity: Coating materials should high surface emissivities so that major portions of the incident heat are emitted away;

7) Resistance to mechanical erosion: Coating materials should provide resistance to mechanical erosion that happens as a result of various particles present in the exhaust gas coming from the combustion chamber;

8) Close or match coefficient of thermal expansion: The coating material has a coefficient of thermal expansion (CTE) close to that of the substrate material to minimize thermal stresses when subjected to high temperatures and prevent cracking in the topcoat layer;

9) It has a high flexural strength; and

10) It has a high fracture toughness.

\section{RESULT AND DISCUSSION}

There are no experimental or design results for this research. Hence, discussion is not possible.

\section{CONCLUSION}

Having considered the various ceramic materials for thermal barrier coating in internal combustion, one could see that $7-8 \%$ yttria stabilized zirconia which has a matched CTE, low thermal conductivity and high thermal shock resistance is highly recommended in ICEs applications. Applying thermal barrier coating technique on engine parts especially cylinder, piston heads and exhaust valves would increase the combustion temperature and reduce loss of heat to the coolants.

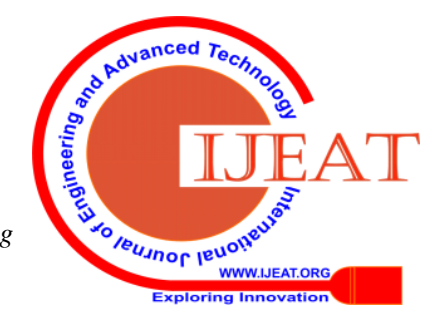


This was possible due to the low thermal conductivity and close or match coefficient of thermal expansion of the coating material with that of the substrate material to minimize thermal stresses when subjected to high temperatures and prevent cracking in the coating layers;. Increase in combustion temperature improves engine performance by increasing the brake thermal efficiency, reducing brake specific fuel consumption (BSFC) and negative effect of gas emissions.

\section{REFERENCES}

1. B. Ekrem. "Thermal analysis of functionally graded coating Al-Si alloy and steel pistons." Journal of Energy Conversion and Management, vol. 202(16), 2008, pp. 325-336.

2. J. I. Ramos, Internal Combustion Engine Modeling, $2^{\text {nd }}$ ed. USA: Taylor \& Francis, 1989, p. 278.

3. J. B. Heywood. Internal Combustion Engine Fundamentals, International ed. USA: McGraw-Hill Book Company, 1998, pp. 930.

4. B. H. Robert, Plasma-Spray Coating Principles and Applications, $2^{\text {nd }}$ ed.New York: VCH Publishers, Inc., 1996, p. 352.

5. E. Büyükkaya. "Ceramic coating application and performance analysis in a diesel engine." Unpublished Msc Thesis, Istanbul Technical University, Turkey, 1994, p. 80.

6. B. Ekrem, and C. Muhammet, "Thermal analysis of a ceramic coating diesel engine piston using 3D finite element method (FEM)." Journal of Surface and Coatings Technology, vol. 202, 2007, pp. 398-402.

7. K. G. Aditya, and K. T. Vinay, "Design analysis and optimization of internal combustion engine piston using CAE tool ANSYS." Aditya Kumar Gupta International Journal of Engineering Research and Applications, vol. 4(11), 2014, pp. 4-10.

8. K. Manish, "A finite element thermo-mechanical stress analysis of internal combustion engine piston." International Research Journal of Engineering and Technology, vol. 4(6), 2017, pp. 1976-1981.

9. M. Klaus, and T. Helmut, Handbook of Diesel Engines. New York: Springer Heidelberg Dordrecht, 2010, p. 634.

10. P. I. Frank, and P. D. David, Introduction to Heat Transfer. $3^{\text {rd }}$ ed. UK: John Wiley \& Sons Ltd, 1996, pp. 258.

11. R. F. Colin, and T. K. Allan, Internal Combustion Engines Applied Thermosciences, $3^{\text {rd }}$ ed. UK: John Wiley \& Sons Ltd, 2016, p. 477.

12. M. G. Hocking, V. Vasatasree, and P. S. Sidky, Metallic and Ceramic Coatings, High Temperature and Applications, London. UK, 1989, p. 213.

13. D. A. Marks, and A. L. Boehman, The Influence of Thermal Barrier Coatings on Morphology and Composition of Diesel Particulates, 1997 International Congress \& Exposition Detroit, Michigan, USA, 1997, pp. 51-60.

14. T. Hejwowski, and A. Weronsk, "The effect of thermal barrier coatings on diesel engine performance." Journal of Vacuum Surface Engineering, vol. 65, 2002, pp. 427-432.

15. R. Kamo, D. Assanis, and W. Bryzik, "Thin thermal barrier coatings for engines." SAE, USA, 1989, pp. 48-60.

16. R. Kamo, W. Bryzik, M. Reid, and M. Woods. Coating for Improving Engine Performance, 1997 International \& Congress and Exposition, USA, 1997, pp. 49-60.

17. H. Yaşar, Effects of Thermal Barrier Coating to Performance of a Turbocharged Diesel Engine. Unpublished $\mathrm{PhD}$ Thesis, Istanbul Technical University, Istanbul, Turkey, 1997, pp. 68.

18. D. Assanis, K. Wiese, E. Schwarz, and W. Bryzik, The Effects of Ceramic Coating on Diesel Engine Performance and Exhaust Emissions, 1991 International \& Congress and Exposition, USA, 1991, pp. 250-259.

19. H. Samadi, and T. W. Coyle, Alternative thermal barrier coatings for diesel engines, 2004 5th Congress of Iran Ceramic Society, 2004, pp. $1-8$.

20. H. Schneider, J. Schreuer, and B. Hildmann, "Structure and properties of mullite - a review." Journal of the European Ceramic Society, vol. 28(2), 2008, pp. 329-344.

21. H. Samadi, and E. García, "Thermal conductivity of plasma sprayed forsterite/mullite coatings.” Ceramics International, vol. 40(9), 2014, pp. 13995-13999.

22. S. Lakshmanan, B. G. Ranjith, S. Sabesh, and M. Manikandan, "Investigation of thermal barrier coating on IC engine piston. International Journal for Research in Applied Science \& Engineering Technology (IJRASET), vol. 5, 2014, pp. 67-72.
23. H. Wang, and H. Herman, "Thermomechanical properties of plasmasprayed oxides in the $\mathrm{MgO}-\mathrm{Al}_{2} \mathrm{O}_{3}-\mathrm{SiO}_{2}$ system." Surface and Coatings Technology, vol. 42(3), 1990, pp. 203-216.

\section{AUTHORS' PROFILE}

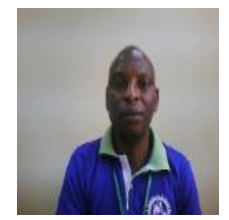

Engr. Isaac Oamen Festus holds B.Eng (Mechanical Engineering) and M.Eng (Thermo-Fluids/Therma Power Engineering) from the Ambrose Alli University, Ekpoma Edo State, Nigeria in 2003 and 2008, respectively. He is presently doing his $\mathrm{PhD}$ in the same University. He works as a lecturer in the Department of Mechanical Engineering, Faculty of Engineering in Edo University Iyamho located in Uzairue, Edo State. He has over 40 publications and his research interest includes thermal and structural analyses, finite element analysis, 2D and 3D modelling in SolidWorks, AutoCAD and ANSYS softwares, computational fluid dynamics and analysis of internal combustion engines. He is a member of Nigerian Society of Engineers and a registered engineer with the Council for the Regulation of Engineering in Nigeria. His email address is isaac.oamen@edouniversity.edu.ng and mobile phone number as 08037758993

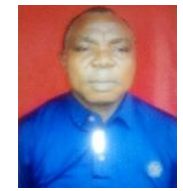

Engr. Edema Ofuafo Anthony holds B.Sc (Mechanica Engineering) and M.Tech (Mechanical Engineering) from the University of Lagos, Lagos State and University of Science and Technology, Port-Harcourt, Rivers State, respectively. He works as a lecturer in the Department of Mechanical Engineering, Delta State Polytechnic, Otefe-Oghara, Delta State. He is a member of Nigerian Society of Engineers and a registered engineer with the Council for the Regulation of Engineering in Nigeria. His email address is aoedema@gmail.com and mobile phone number as 08063347795. 